\title{
Agôn
}

Revue des arts de la scène

Critiques | Saison 2012-2013

\section{Je suis un metteur en scène japonais, de Fanny de} Chaillé

Le Corps des mots

\section{Marion Siéfert}

\section{CpenEdition}

Journals

Édition électronique

URL : http://journals.openedition.org/agon/2357

DOI : 10.4000/agon.2357

ISSN : 1961-8581

Éditeur

Association Agôn

\section{Référence électronique}

Marion Siéfert, "Je suis un metteur en scène japonais, de Fanny de Chaillé », Agôn [En ligne], Critiques,

mis en ligne le 18 décembre 2012, consulté le 23 septembre 2020. URL : http://

journals.openedition.org/agon/2357; DOI : https://doi.org/10.4000/agon.2357

Ce document a été généré automatiquement le 23 septembre 2020.

Association Agôn et les auteurs des articles 


\section{Je suis un metteur en scène japonais, de Fanny de Chaillé}

Le Corps des mots

Marion Siéfert

\section{RÉFÉRENCE}

Je suis un metteur en scène japonais de Fanny de Chaillé - Théâtre de la Cité Internationale à Paris - du 3 au 21 décembre (relâche les mercredis et les dimanches), informations :

http://www.theatredelacite.com, 01.43.13.50.50.

1 C'est un spectacle qui donne tout à voir sans aucune illusion, qui se montre au travail tout en fabriquant de l'art; qui se donne et qui se montre à nous, ses spectateurs, exigeant de notre part autre chose qu'une simple contemplation. Il est rare, qu'au théâtre, on sollicite vraiment notre regard; que l'on « joue contre le public » (Thomas Bernhard), sans l'exclure pour autant du processus de représentation. Je suis un metteur en scène japonais a besoin de ses spectateurs, pour créer une vision cohérente à partir de ses éléments dispersés. La première image du spectacle est éclatée, répartie entre les différents acteurs de la représentation: une danseuse vêtue de noir, au visage de poupée impassible, est dirigée comme une marionnette par trois manipulateurs, tandis qu'un musicien accompagne au ukulélé leurs déplacements et qu'un récitant lit Minetti de Thomas Bernhard, interprétant à lui seul les différents personnages. Cette répartition scénique est celle du bunraku, un théâtre de marionnettes japonais. 


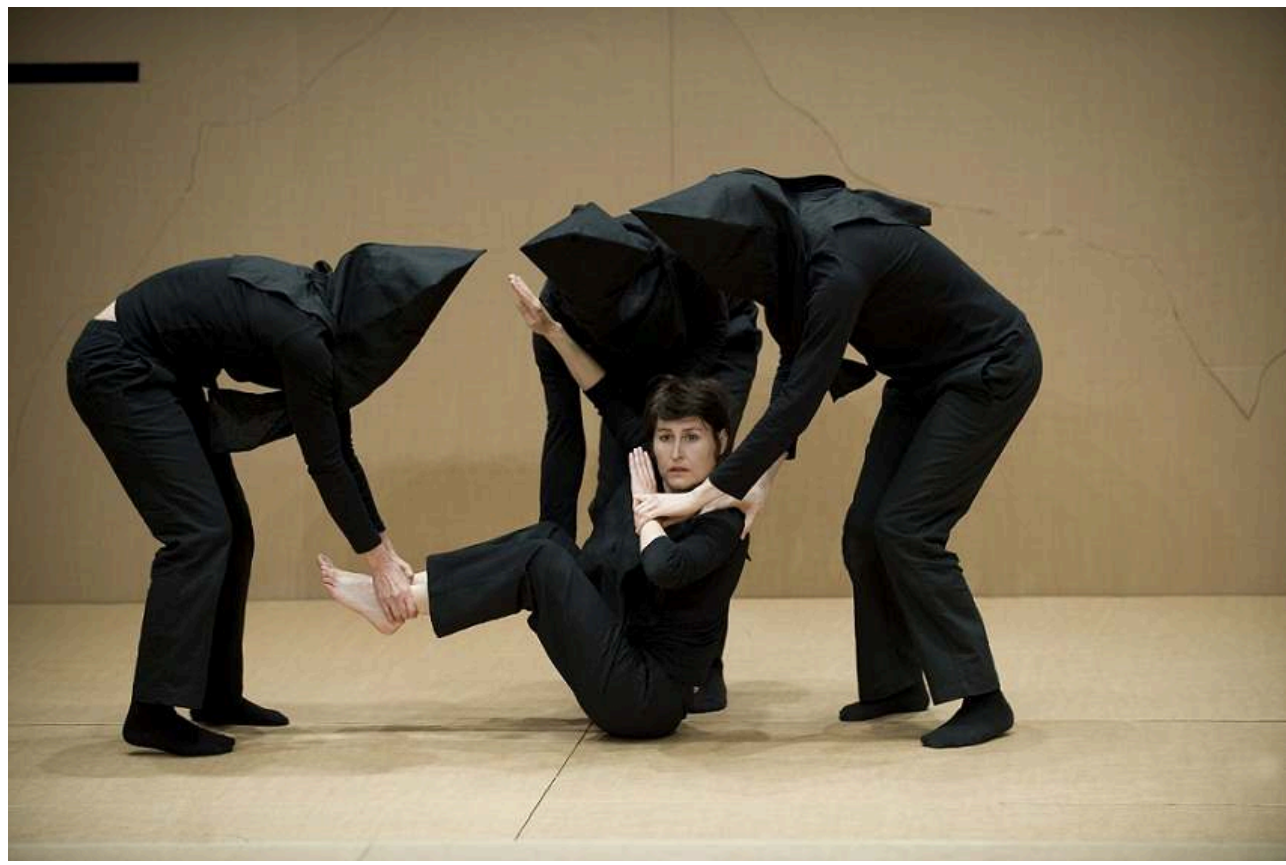

(c) Marc Domage

2 L'idée de Fanny de Chaillé est de prendre au pied de la lettre, et Minetti, et la manipulation chère au bunraku. Prendre au pied de la lettre, cela signifie travailler la littéralité d'un texte et de ses métaphores; manipuler, c'est travailler au corps le langage. Au détour de ce qu'elle appelle une «bulle japonaise» (la présentation au public d'un cliché sur ce "Japon en carton"), une leçon d'origami, une danseuse fait office de feuille de papier que l'on plie sans ménagement, jusqu'à ce qu'émerge sous nos yeux une cocotte-danseuse en papier. Prendre Minetti comme une leçon d'origami, telle est la méthode de Je suis un metteur en scène japonais, si bien que lorsque le mot dit "plier ", le corps se plie; lorsque Bernhard écrit «mettre l'histoire entière sur la tête ou la tête sur l'histoire entière », le comédien est soulevé et mis sur la tête. Le langage et ses métaphores - est exploré dans sa littéralité la plus drôle et la plus prosaïque. Minetti n'est ni interprété, ni représenté, mais il est incarné. Il ne s'agit plus seulement de donner du sens aux mots, mais de leur donner du corps; de prendre le texte dans sa matérialité, comme source véritable d'inspiration pour des mouvements, de se servir de sa structure répétitive, mais aussi de ses expressions très figurées.

3 Dans ce spectacle, Fanny de Chaillé se fantasme metteur en scène japonais du grand texte de Thomas Bernhard sur le théâtre : Minetti, pièce dans laquelle l'acteur Bernhard Minetti explique les raisons pour lesquelles il a déserté les plus grandes scènes d'Europe, animé par la volonté de rester intègre à son art et de ne pas sombrer dans les affres consciencieuses, respectueuses et soporifiques du classicisme, cher aux grandes institutions culturelles somnolentes. À rebours des adaptations sérieuses et grandiloquentes des textes de Bernhard, qui prolifèrent sur les scènes de nombreux théâtres parisiens, Je suis un metteur en scène japonais impose sa méthode de travail et nous la montre à l'œuvre, si bien que l'on assiste tout autant à la construction d'un spectacle, qu'à sa forme artistique finale. À la différence des mises en abyme classiques, le propos de Fanny de Chaillé n'est pas de nous offrir un spectacle dans le spectacle, lieu commun des réflexions sur le théâtre, mais de nous montrer le décomposé d'une 
genèse. La structure du bunraku lui permet d'exposer méthodiquement son travail, d'expérimenter des formes nouvelles et personnelles et de nous faire comprendre pourquoi et comment l'illusion théâtrale prend : d'abord soigneusement isolés selon les codes du bunraku, les éléments qui constituent le théâtre sont ensuite associés dans des combinaisons différentes et originales, si bien que c'est un discours sur l'art qui prend forme peu à peu sous nos yeux. Loin de l'éternel topos du work in progress, Je suis un metteur en scène japonais est une œuvre achevée, qui nous présente sa méthode dans une dramaturgie extrêmement construite.

4 Rarement on aura monté un discours philosophique et artistique avec une telle force corporelle, en faisant directement appel au sens esthétique du public, c'est-à-dire à sa capacité à entendre et à construire une vision artistique, à faire le lien entre différents langages. Sans se départir de son humour, Je suis un metteur en scène japonais ose tenir un discours sur le théâtre, sans jamais basculer dans l'entre-soi. 